\title{
Harmonics Analysis of Thyristor controlled Reactor circuits
}

\author{
T.Vijayakumar, .A.Nirmalkumar
}

\begin{abstract}
Harmonics that arise from the interaction of thyristor controlled reactors (TCRs) and power systems are difficult to analyze. Two methods are described. The first develops a Fourier matrix model for the TCR. The coupling between the harmonics through the system impedance is clearly shown. The second method uses state variable analysis to write the system equations for a circuit containing a TCR. The systems of equations that result are linear with time varying coefficients. Using linear system theory statements and resonance can be made. Simulation of FC-TCR was done and FFT analysis is performed using matlab.The spectrum for the current is presented.
\end{abstract}

Keywords:Static VAR Compensators, Harmonics, Harmonic Analysis.

\section{INTRODUCTION}

As switching circuit in power systems proliferate there is an increasing need to accurately model the harmonics that they introduce and to understand the resonance problems they can cause. Different methods have evolved to study these problems. They can be put into three different categories. One looks at the time dependent functions by solving the equations through digital integration techniques. In another, the individual harmonics are looked at in the harmonic phasor space, treating the time functions as complex algebraic equations. In the third, the state equations are formulated and then investigated using linear system theory.

Individual harmonics are usually calculated using the first two methods. The circuit can be solved in the time domain and the results analyzed for its harmonic content. Another way is to solve the circuit in the frequency domain, treating each harmonic as a phasor. This approach can be more powerful, although a major difficulty is modeling the coupling between harmonics of different frequencies which naturally occur in nonlinear and switching circuits. Harmonics are not calculated using state variables since a closed form solution can seldom be found except in the simplest cases. The strength of this approach is its great theoretical depth which can give understanding to the problem and which can give understanding to the problem and which can allow qualitative assessments to be made.

Several methods for handling harmonic producing circuits in the frequency domain have been proposed. The paper [1]

Manuscript received June 9, 2009

F. T.vijayakumar is with Karpagam College of Engineering, Coimbatore, 641032, INDIA (phone: +91-422-2669042; fax: 91-422-2669045; e-mail: vijaypoy@yahoo.com).

S. A.Nirmalkumar is with Bannari Amman Institute of Technology, Sathyamangalam, INDIA (e-mail: ank_hod@yahoo.co.in). uses a complex conjugate phasor space to calculate the harmonics in nonlinear magnetic circuits. A similar approach will be taken in the first part of this paper. It will show the coupling of harmonics in switching circuits, concentrating on the simple case of a naturally commutated thyristor controlled reactor (TCR).

A harmonic admittance matrix will be developed for the TCR, satisfying $I_{g}=\left[Y_{T C R}\right] V_{T}$, where $I_{g}$ is the current and $V_{T}$, is the terminal voltage of the TCR. It is the off diagonal elements of $\left[\mathrm{Y}_{\mathrm{TCR}}\right]$ that model the interaction between the harmonic voltage of one frequency to the harmonic current of another frequency.

The state equations for a TCR circuit will also be developed. They constitute a set of linear differential equations with periodic coefficients. Using linear system theory, conditions for resonance will be investigated. This will be compared with resonance conditions found by the harmonic admittance matrix model.

Continuous and discrete signal analysis is given in [2].Principles and applications of static TSC is given in [3].Analysis and synthesis of linear time varying systems is given in [4]. Classical and controlled differential equations are given in [5].Equivalent circuit and frequency response of static Var compensator is given in [7]. The above literature not deal with harmonic analysis using matlab. This paper deals with frequency spectrum for the current through TCR.

\section{FC-TCR SYSTEM}

The circuit of FC-TCR system is shown in fig 1.

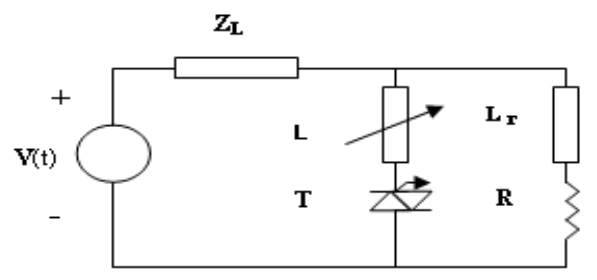

Fig 1. Circuit of TCR

$\mathrm{V}(\mathrm{t})$ is the input $\mathrm{AC}$ source and $\mathrm{ZL}$ indicates the line impedance.TCR is realized using $\mathrm{L}$ and antiparallel switch $\mathrm{T}$. Load is represented as a series combination of RC and LL.

\section{Simulation RESUlts}

The simulation was done using Matlab Simulink version 7.2 and the results are presented here. Current waveform for single phase TCR circuit is shown in Fig 2a. Real and reactive powers with $\alpha=162^{0}$ is shown in Fig 2b.The bidirectional switch is implemented using 4 diodes and one thyristor. The current through TCR with $\alpha=144^{0}$ is shown in 
Fig 3a.The real and reactive powers with $\alpha=144^{0}$ is shown in Fig 3b. It can be seen that the current can be varied by varying the firing angle. The current decreases with the increase in firing angle. Thus the reactive power can be varied by varying the firing angle.

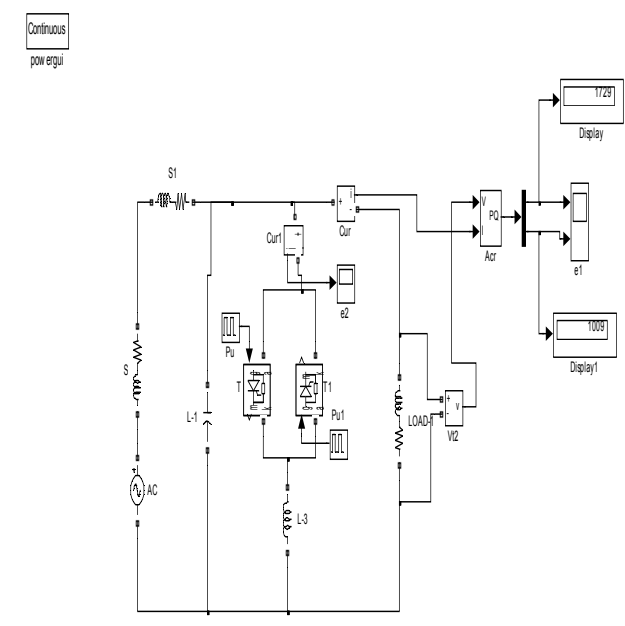

Fig.1b.FC- TCR circuit model

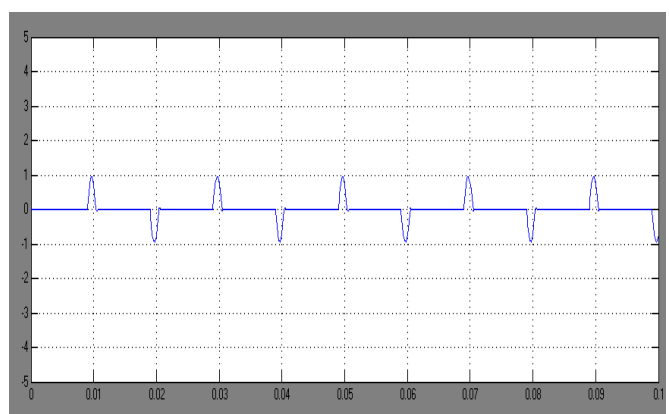

Fig 2a TCR Current Waveform with Alpha $=162$ Deg

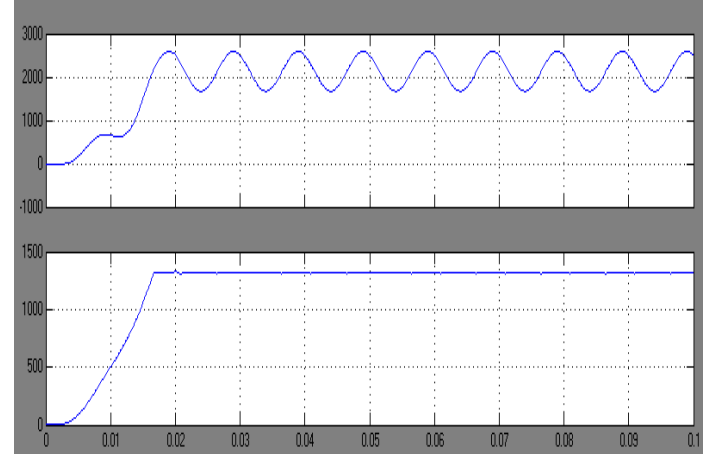

Fig $2 b$ Real \&Reactive Power with Alpha $=162$ Deg

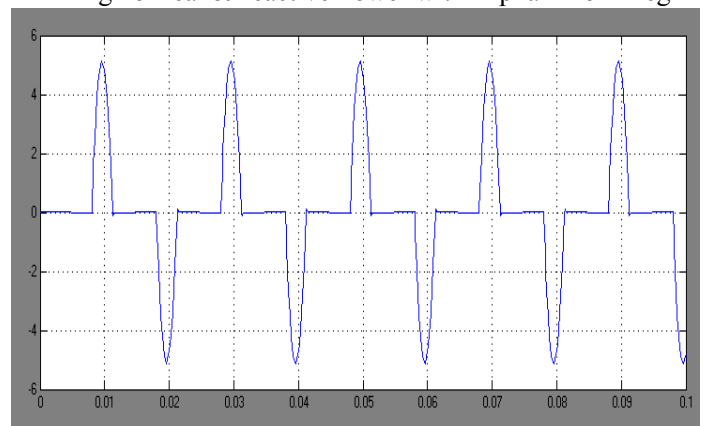

Fig 3a TCR Current Waveform with Alpha = 144 Deg

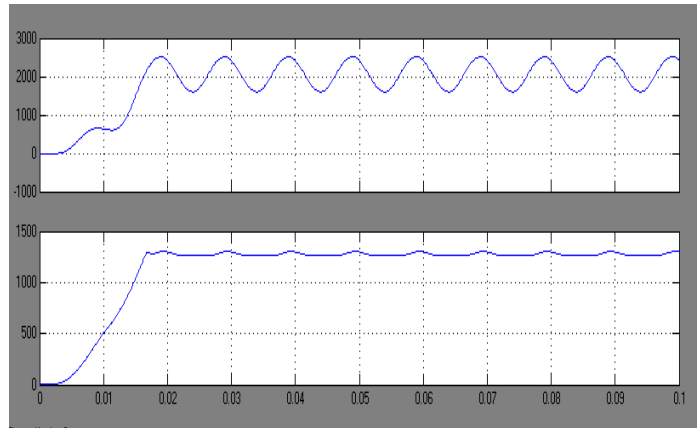

Fig 3b Real \&Reactive Power with Alpha = 144 Degree

Current through TCR with alpha $=120$ degree is shown in Fig 4a.The frequency spectrum for this case is shown in Fig 4 b.. THD is $41 \%$.Current through TCR with alpha $=100 \mathrm{deg}$ is shown in Fig 5a. and the corresponding spectrum is shown in Fig 5b.THD increases to $114 \%$.

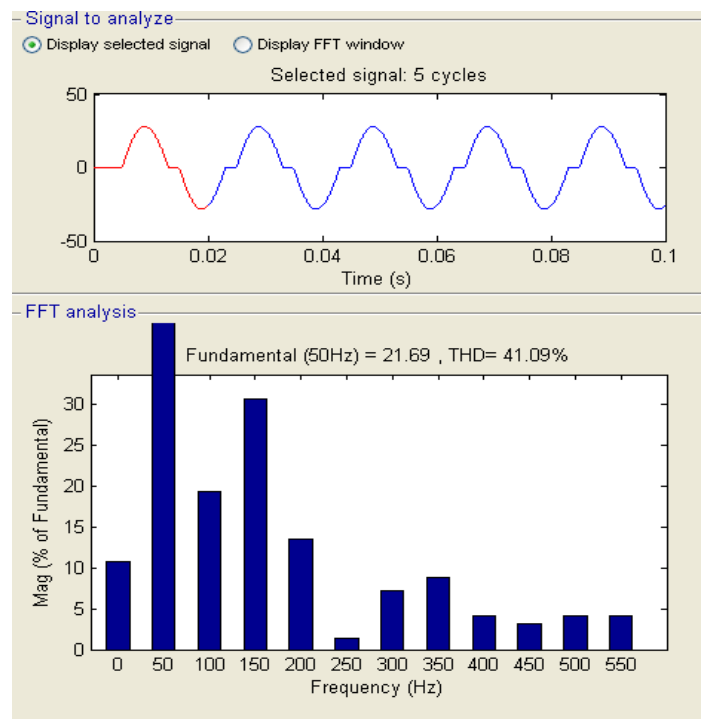

Fig 4 b.Spectrum with alpha $=120$ deg .

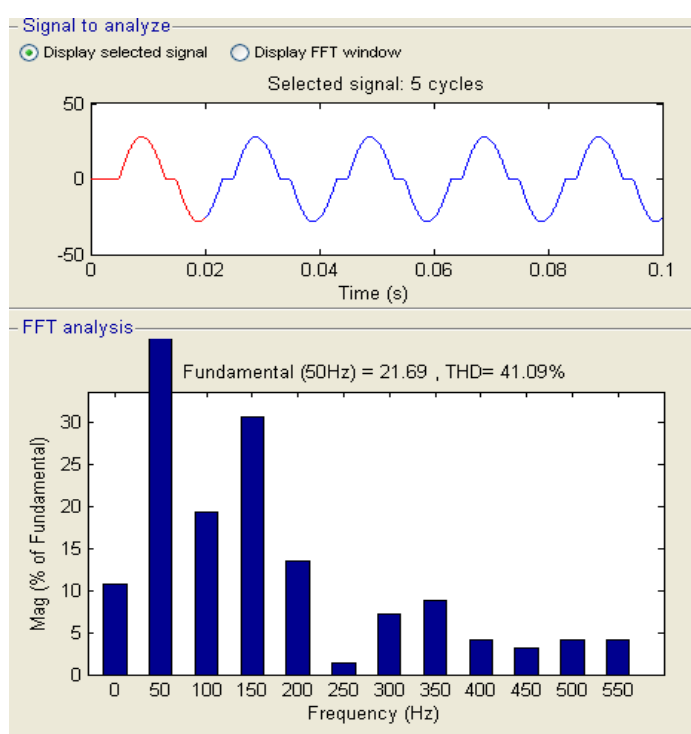

Fig $5 b$. Spectrum with alpha $=100 \mathrm{deg}$

\section{CONCLUSIONS}

In the case of TCR there is always an interaction between the odd harmonics. If there are even harmonics on 
the system then there is interaction between all the harmonics. For accurate modeling of the TCR in a power system these interactions need to be taken in to account. One way to do this is to use the Fourier matrix equations. This method works well in many situations including investigating the effects of ambient harmonics. The accuracy of this method decreases near resonance points.

Harmonic analysis was done for the current with various firing angles and the results are presented. The harmonics increase with the increase in the firing angle.

\section{REFERENCES}

[1] A.Semlyen, E. Acha, J. Arrillage; "Newton-Type Algorithms for the Harmonic phasor Analysis of Non Linear Power Circuits in periodical steady state with special reference to Magnetic Non-linearities"IEEE Trans on power delivery, Vol.3, pp.1090-1098, July 1988

[2] Clare D. McGillem and George .Cooper; Continuous and Discrete signal analysis Holt Rinehart and Winston, New York 1974;pp108-109.

[3] L.Gyugyi, R.A.Otto, and T.H Putman; "Principles and applications of static Thyristor-Controlled Shunt Compensators"IEEE Transactions on power Apparatus and systems ,Vol.PAS - 97, No. 5, pp 1935 - 1945, Sep/Oct 1988.

[4] H.D'Angelo: Linear Time - Varying Systems:Analysis and Synthesis:Allyn and Bacon,Boston,1970:pp195.

[5] D.L.Lukes Differential Equations Classical and Controlled: Academic Press, Newwork,1982:pp 172-175.

[6] L.J.Bohmann, R.H.Lasseter:"Equivalent circuit for frequency response of a Static Var Compensator" IEEE Trans.Power Systems, Vol.PWRS -1, No.4,pp 68-74,Nov 1996.

T.Vijayakumar has obtained his B.E. Degree from Bharathiar University and M.E. degree from Annamalai University in the year 1998 and 2001 respectively. He has 10 years of teaching experience. He is presently a research scholar in Anna University. His research area is on reactive power control in power systems.

Dr. A. Nirmalkumar has obtained his B.E. Degree from Calicut University and M.E. degree from Kerala University in the years 1972 and 1976 respectively. He has completed his Ph.D in the area of Power Electronics from Bharathiar University in the year 1989. He has secured a gold medal from Institution of Engineers in the year 1989. He has 30 years of teaching experience. He is presently working as professor and Head of EEE dept, BIT, Sathyamangalam. His research area is power quality in power systems. 